\title{
Multidimensional Pareto optimization as an approach for site-specific building refurbishment solutions applicable for life cycle sustainability assessment
}

\author{
York Ostermeyer • Holger Wallbaum • Friedrich Reuter
}

Received: 7 May 2012 / Accepted: 15 January 2013 /Published online: 14 February 2013

(C) The Author(s) 2013. This article is published with open access at Springerlink.com

\begin{abstract}
Purpose This paper addresses the application and potential of LCSA in the built environment with a focus on refurbishments of residential buildings. It specifically addresses the phenomenon of interchange of building technologies efficiencies under different life time assessments from economy, ecology and social fields. An approach of optimization rather than hard target numbers is proposed as win-win-win situations are unlikely.

Methods A multidimensional Pareto optimization methodology, using LCC, LCA combined with first stages of a social assessment in a feasibility study but potentially later full SLCA, is proposed, which site-specifically visualizes the interchange between different options in building design or modification, and evaluates optimal overall concepts. LCA and LCC are used to analyze a case study from an EU project named BEEM-UP in which solutions for largescale uptake of refurbishment strategies are developed. Social frame conditions are taken into account by identifying the driving technologies and feeding the consequences of their implementation for the residents into the tenant involvement part of the project.

Results and discussion The calculations prove that the general assumptions leading to the methodology hold true at
\end{abstract}

Responsible editor: Hanna-Leena Pesonen

Y. Ostermeyer $(\bowtie)$

Building Physics, Chalmers University of Technology,

41296 Gothenborg, Sweden

e-mail: york.ostermeyer@chalmers.se

H. Wallbaum

Sustainable Building, Chalmers University of Technology,

41296 Gothenborg, Sweden

F. Reuter

LUWOGE consult GmbH, Donnersbergweg 2,

67059 Ludwigshafen, Germany least for this case study. A clear Pareto-optimal curve is visible when assessing LCC and LCA. The example buildings results show certain systems to be dominating clusters on the figures while others clearly can be identified as not relevant. Several of the driving technologies however fail to be applicable because of social frame conditions, e.g., clear requests by the tenants. Based on the conclusions, the potential for including SLCA as a third dimension in the methodology and possible visualization options are discussed.

Conclusions The development in the field of social indicators in the building sector has to be strengthened in order to come up with a holistic picture and respectively with appropriate responses to current challenges. While some solutions identified in the LCC/LCA assessment also have good social characteristics, several others have not and solutions identified as lacking might have social advantages that are currently left out of consideration The upcoming Standards EN 15643-5 and ISO 15686-X are a promising step in this direction as is the work to create a conceptual framework for impact assessment within SLCA by the scientific community.

Keywords Building assessment · Building design · Building refurbishment · Decision support · LCSA · Optimization · Refurbishment $\cdot$ Tools and methods

\section{Introduction}

1.1 Relevance of the building sector for global sustainability and needs for holistic assessment

The built environment is a central aspect of daily human life (Dumreicher and Kolb 2008). People in industrialized countries spend about $80 \%$ of their time in buildings (Frontczak et al. 2012). In emerging or developing countries, the percentage is still higher than $50 \%$ (UN 
Habitat UE 2008). It can therefore be assumed that buildings have a strong influence on individuals as well as the society they live in.

Building processes are also among the most cost intensive processes that we come into contact with. As for residential buildings, many people take 20 or 30 years, or even more, to pay back their home loans (Kreditanstalt für Wiederaufbau 2012). Though in life cycle costing of office buildings the salaries of the employers are much greater factor than the lifetime costs of the building the work in, the building costs still hold a solid share of the overall cost leading to increasing efforts for cost reduction in this sector as well.

Finally, building processes contribute to about $70 \%$ of land change, $50 \%$ of material flows and $40 \%$ of global $\mathrm{CO}_{2}$ eq (UNEP 2003). Most current scenarios for limiting climate change to a tolerable degree see improvements in the building sector as one of the key issues necessary for success (Wu et al. 2012).

Having such a strong impact and interchange with environment, society, and economy, the built environment is an excellent example of a sector that needs methodologies for a holistic evaluation, covering all these fields, in order to get to sensible solutions for given situations (Maliene and Malys 2009; Aktas and Bilec 2012).

This clearly requires tools and approaches that assess all three aspects, and evaluate the interchange between them. Following the paradigm of weak sustainability, suitable solutions that achieve an as good as possible overall performance and ideally a minimum performance in all three pillars need to be identified. Most importantly, solutions for which superior alternatives exist for all three pillars should be avoided - only Pareto-optimal solutions should be considered, and only those that achieve a minimum performance in all three dimensions of sustainability.

Refurbishment of buildings is seen as a possible major contribution to lowering the impact of buildings on the environment (European Commission 2010) while being, ideally, economically promising and keeping the social identity of our built environment. On the other hand, regulations are often centered on the sustainability of new buildings (Meijer et al. 2009), and there is a lack of regulations tailored to refurbishment (Femenías and Lindén 2011). At the same time existing buildings have to be seen as a key factor in local identity, and as a hub of socio-ecological development (Council of Europe 2012).

While the main conclusions and proposals made within this paper hold true for new buildings, the focus is kept on refurbishments and its specific aspects. Another reason for the choice of refurbishments as first application case studies is the fact that a lot of frame conditions are set and respective simplifications can therefore be made in the first step.

This paper is divided in four parts. After this introduction, the current situation regarding what LCSA is and needs for future development is described. Then, a case study from an EU project is introduced. Based on the analysis of the current situation, a methodology for multidimensional Pareto optimization is introduced, applied to the case study and the results are discussed. Finally, the needs of SLCA for the building sector and first starting points are addressed.

\section{Current situation}

\subsection{Life cycle thinking in the building sector}

Sustainability concepts and most buildings labels in the building sector are essentially based on the capital stock model introduced by the World Bank in 1994.

$C_{\mathrm{SD}}=C_{\text {Environment }}+C_{\text {Economy }}+C_{\text {Society }}$

Strong Sustainability according to this model demands that no capital factor should be diminished in the long-term.

Weak Sustainability according to the model demands that the total capital should not be diminished in the long-term (Maite Cabeza Gutés 1996).

Because of the tradeoff described later in this paper, strong sustainability is very often not applicable in the building industry, as increased social benefits often come with economic costs without increases in revenue. This conflicts directly with strong sustainability. Current discussion therefore focuses on weak sustainability and the question of factor mobility.

In common practice, however, the idea of sustainability as defined by the triple-bottom approach and its three dimensions of sustainability is not visible in the building sector.

Most importantly, SLCA is still weak and uncommon, keeping a whole pillar often out of consideration in many assessments (Kaatz et al. 2006; Dreyer et al. 2006; Reitinger et al. 2011). Very often social aspects, like increased comfort due to less draft, are connected to or a side effect of an ecologically driven refurbishment, like better insulated and airtight walls, and used in communication with residents in order to gain their acceptance for the measures (Jörgensen 2009). This often leaves decisions in the building sector to a weighting of economic and ecological aspects with a design-based social annex in the best of cases - very often the necessary investment costs are simply dominating everything else (Allacker 2012)

When analyzing building projects, it can be stated that often neither the environmental nor the economic aspects follow a lifetime perspective. While economics focus almost entirely on the investment costs (Feige et al. 2011) the environmental part focuses on the operation phase and the running energy consumption. Both facts can be explained 
historically. Environmentally, energy consumption was the dominating aspect of environmental impact assessment for a long time (Marceau and VanGeem 2006). Only current stateof-the-art buildings achieve a level of energy efficiency in which the initial (gray) impact covers about half of the overall lifetime impact (Güttinger and Kasser 2009; Blengini and Di Carlo 2010). From the economic point of view, the running heating costs, driven by energy consumption, were of minor relevance as energy was cheap. Furthermore, a party other than the investor of the construction process is often covering the running costs. The later costs, like cleaning and depreciation, are the dominating running cost in many office buildings.

Obviously, a lifetime perspective needs to be implemented in both areas of the building sector in order to improve its sustainability performance. For the environmental part, this means an increasing need to connect tools for energy balance calculation with environmental product and process databases. For the economic part, not only the usage phase has to be considered, but very likely investment models must be modified in order to connect the investor with the running costs, allowing the investing party to profit from good concepts during the usage phase. It is because of the special situation in single-family homes, were the investor is very often also the user and therefore profiting directly from low investment as well as low running costs and therefore seeking an optimal balance, that buildings from this field have been drivers of technological development and know-how such as in the Passive house movement.

In general, LCA and LCC certainly are very promising concepts for the building sector, with the potential to solve the problems related to the currently limited system boundaries (Optis and Wild 2010). However, certain barriers currently keep life cycle methods from being applied on a large scale, with the problems of finding a suitable functional unit and a sensible target being chief among these barriers. SLCA is certainly needed in order to provide decision makers with a holistic decision basis. Currently, the weakest dimension of sustainability in the building sector, SLCA needs to be strengthened, and indictors tailored specifically to the buildings sector need to be developed towards this goal.

\subsection{Site-specific solutions vs. hard targets}

Currently, EU legislative regulations and most labels give hard or semi-hard targets for new buildings as well as for refurbishment measures (DIN EN 18599 2007; MINERGIE 2012). Targets are somewhat adaptive as, for example, the minimum running prime energy demand is often related to the surface to volume ratio of the building (DIN EN 18599 2007). Such targets are commonly designed in a way that there is a certain incentive to build buildings with sensible surface to volume ratios without making other approaches impossible to realize when other frame conditions demand them. In buildings, this could mean compensating with more insulation or a more efficient heating system.

Hard or semi-hard targets generally made sense when they were created, but are becoming increasingly inappropriate as the system boundaries and the number of indicators and dimensions of sustainability aspects increase.

Though still partly based on regional legislative frameworks, building labels such as the one from the DGNB (DGNB 2012) try to approach this problem by including site quality as one of their criteria or create country or climate specific versions of their labels, such as BREEAM (2012), which is always based on the regional legislative framework. LEED (2012) is currently setting up a region specific approach.

However, for refurbishments, the site is fixed, as it is in many cases for new buildings, and from an environmental point of view, the frame conditions that made the building happen in the first place are more complex than simple site quality. Buildings are often already connected to complex networks within the city, and now in the case of refurbishments have to be optimized based on our current understanding of sustainability and currently perceived problems, such as anthropogenic climate change. A change of site is very often simply not an option, regardless of the potential such a measure would have. This leaves some buildings at a severe disadvantage in their efforts to achieve the hard targets, while in other cases it keeps planners from realizing optimal buildings, as the site does not allow for easy achievement of the hard targets. Very often hard targets either make buildings more difficult to realize, especially from an economic point of view, or less well performing than would be possible as only the minimal target levels are aimed for.

The central problem with legislative approaches is the focus on minimal performance levels, while the central problem with building labels is the attempt to achieve a maximum performance in all areas. As maximum performance in all dimensions is generally accepted to be difficult in the building sector, this often results in the labeling of only lighthouse projects in which costs either do not matter for reasons of prestige, or that follow entirely different economic rules than the bulk of the market. A promising step is the implementation of minimal performance levels in all associated criteria in order to achieve a certain overall status or ranking (for example, a DGNB Gold ranking demands at least a silver ranking in each sub criteria) (DGNB 2012).

Especially when considering refurbishments, the options for the site should be measured against each other instead of hard targets. This allows for the realization of optimal solutions instead of realizing, for example, a certain level of energy efficiency regardless of costs. Instead of naming a 
certain performance as a minimal target, the recommendation should be: "As good as possible". Of course, the value of such an optimization approach depends heavily on the indicators chosen. These should cover all relevant aspects of the building process. Referring to the introduction, all three pillars of sustainability should be covered with suitable indicators tailored to the specific conditions of the building sector.

As an alternative to the race toward maximum performance, an optimum performance that achieves a sensible balance of all dimensions of sustainability involved should be aimed for in order to achieve a massive upscaling effect.

The definition proposed and used within this paper according to this would be:

- Maximum performance: best possible performance according to one indicator or in one dimension of sustainability, and therefore not affected by weighting.

- Optimal performance: best possible overall performance over several indicators or dimensions of sustainability, affected by weighting.

\subsection{Tradeoff between different indicators and dimensions of sustainability}

Technologies perform differently when evaluated with different indicators.

A similar effect can be observed when comparing results of economic and ecological assessments of the same technology or concept (LEED 2012). The results in many cases do not match, and when assessing different options according to different indicators, each indicator favors a different solution. A very simple example of this is the question of how much insulation should be applied to a building. Past calculations have shown that ecological indicators tend towards greater insulation thicknesses in a Life Time Assessment than economic calculations, even in high energy price increase scenarios (Ostermeyer et al. 2011). This indicates that the most environmentally friendly scenarios will not happen by the market alone, but that incentives from outside are needed, be they in the form of push, pull or other initiatives. The reasons are climate conditions in combination with current energy prices and salaries in the building industry, at least in the industrialized countries of western and northern Europe. In other countries with other frame conditions, the results can differ but it generally needs extreme price scenarios, extreme life spans or negligible wages to make the economic maximum scenarios match with the environmental maximum scenarios.

From current scientific understanding on the complexity of issues related to the built environment, it can be concluded that measures that are not performing maximally according to a single indicator should be taken, but a kind of compromise should be aimed for, optimally balancing the needs of all related fields. In order to find such solutions, the tradeoff between the different fields and indicators must be understood and visualized. While the idea is well established on the material level (Saling et al. 2002), the complex interchanges in buildings ask for further development of the idea to contribute to a more sustainable development on the concept level as well. In general, the interchanges of the different components need to be better understood.

\subsection{Proposed approach}

When thinking about the refurbishment of buildings, a great number of options exist. These cover active technologies, defined as technologies consuming energy in the usage phase (housing services and appliances), and passive technologies, defined as technologies without energy consumption in the usage phase (insulation, window frames and glazing), as well as changes in user behavior through training.

Besides the described problem that different indicators favor different technologies, they are also in a complex interchange concerning their effectiveness. A simple example is the level of insulation of a building and its effect on the heating phase of a building. Non-insulated buildings in the central European climate commonly have a heating phase from September to May. Buildings with a heavily insulated envelope like Passive Houses only have a heating phase from November to March, as the internal heat loads and the solar gains are able to cover the heating demand in the remainder of the year (Passivhaus 2012). The general principle is visualized in Fig. $1 \mathrm{a}$ and $\mathrm{b}$.

The effect of a heating system is directly related to the amount of heat it is required to provide. A system that might be suitable for a building with a large demand (e.g., a heat pump with an excellent COP, but on the other hand, with high investment costs) might be completely oversized or an unrealistic cost factor for a well-insulated building. The general problem is that it is becoming increasingly difficult, even for experts, to make correct assumptions about the exact effects of the interaction of building technologies, especially when considering multiple dimensions of sustainability, site-specific conditions and a large number of indicators.

Options that might look good on paper might not actually be realistically applicable on site. Especially with refurbishment, there is a multitude of frame conditions that can make the application of certain options impossible. Examples range from site conditions (grounding that hinders the application of soil based heat pumps) to social conditions (tenants that cannot temporarily moved out of their homes, making the application of inside insulation rather impossible), as well as legislative aspects (nobody can be forced to limit himself to only one fridge or one TV, however sensible this might be). 


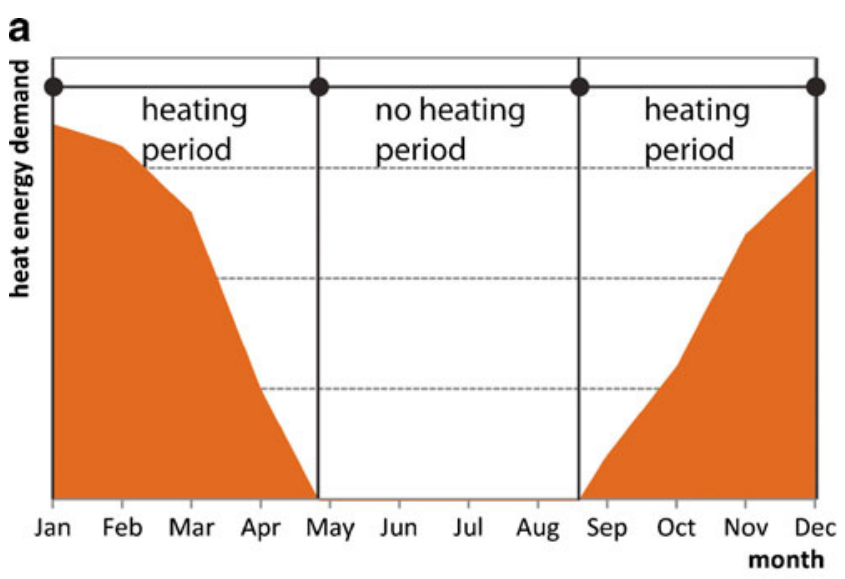

b

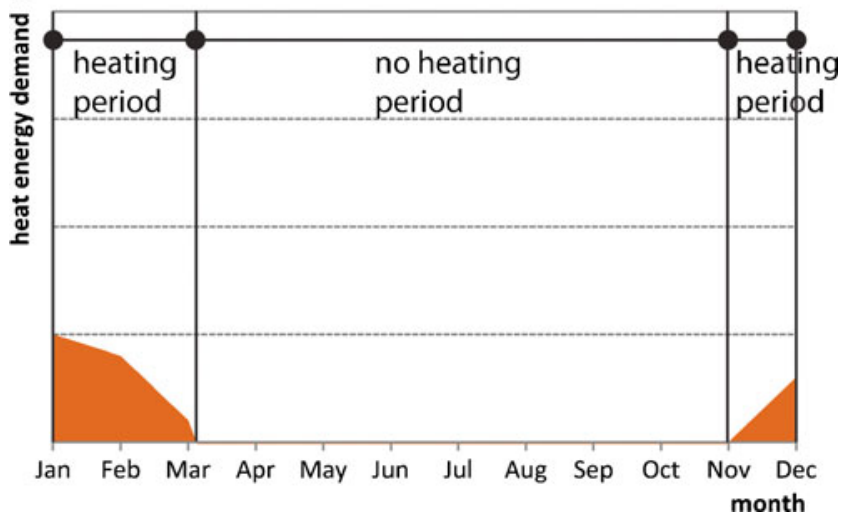

Fig. 1 Different heating phases of buildings with different insulation levels

The proposed approach is based on the following principles:

- A preliminary evaluation of experts should identify suitable options for the site. Unrealistic options therefore are taken out from the beginning.

- The options left should be kept flexible. This allows the option to be tailored to the site and to react to interactions with other options.

- Out of the options available a larger number of concepts are to be generated. This ensures that the optimal solution is not missed due to working with rough guesses.

The interaction between different indicators is certainly a main interest, especially concerning the application of different indicators from each dimension of sustainability. With a large base of experience regarding the nature of interactions, certain types of buildings could be identified in which the planner should emphasize a certain dimension of performance because a unique opportunity presents itself. Sound understanding of these principles can be a valuable contribution not only to individual buildings but also to future city quarter development.
As a first step, analyzing the potential of this approach with an assessment of the interaction between the environmental dimension and the economic dimension of sustainability, for which data is easiest to access, is conducted below. This new approach will be illustrated by the usage of a case study from the EU funded project Building Energy Efficiency for Massive market UPtake (BEEM-UP). The conclusions drawn are then used to describe starting points for SLCA in the field.

\section{The BEEM-UP project as an example case for the methodology}

The project BEEM-UP (BEEM-UP 2012) is conducted under the FP7 framework of the European Union. It aims to refurbish three buildings in three different countries (Fig. 2).

All objects are large-scale residential buildings with a focus on social housing, apartments and flats. All three sites are representative examples in the respective countries of buildings that are due for refurbishment.
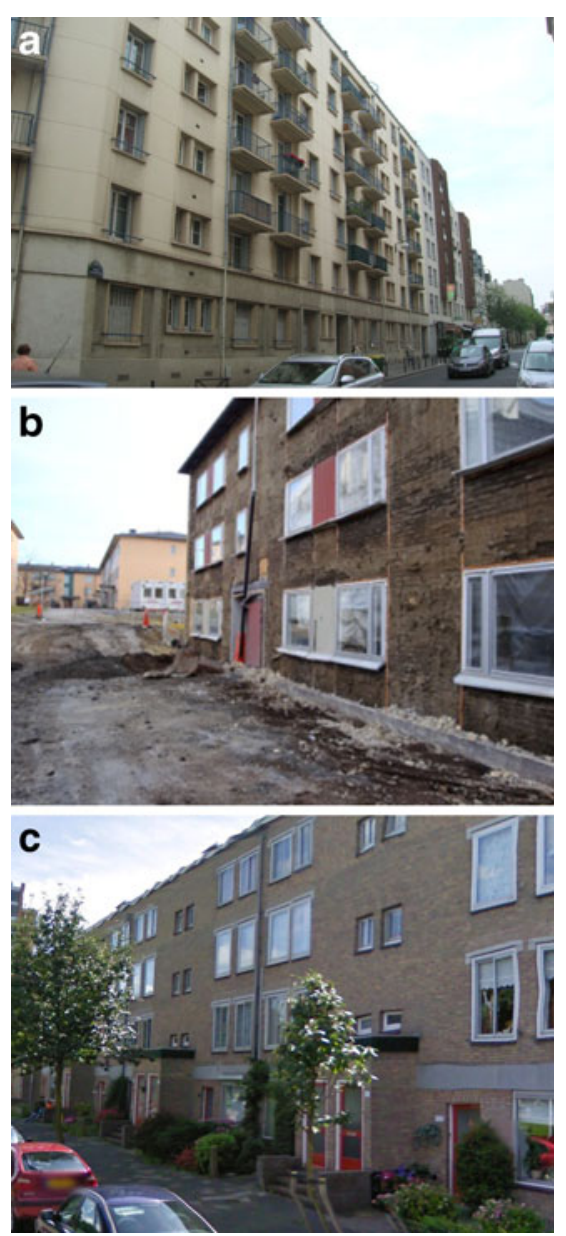

Fig. 2 The three case study sites of the BEEM-UP project: Paris/ France (a), Alingsås/Sweden (b), Delft/the Netherlands (c) 
One of the main goals of the BEEM-UP project is to compare the refurbishment approaches of the different countries, and to provide an exchange regarding related problems and solutions.

The project is therefore ideal to assess the potential for all dimensions of sustainability in a variation of settings.

Furthermore, it is to be proven that refurbishments realizing substantial reductions in energy consumption are economically feasible, practically applicable and socially acceptable, and that they therefore are ready for large-scale uptake. Barriers currently keeping this from happening are to be identified and solutions proposed.

In order to assure the feasibility of the assessment the project involves major players in the construction sector of the respective countries as well as an extensive tenant involvement and cooperation with the academic sector. The exact setup and the methodology of the tenant involvement can be accessed via the project homepage.

All sites have to fulfill certain semi-hard targets, mainly the ones set by the BEEM-UP project outline $(75 \%$ reduction in prime energy heating demand in comparison to the status before refurbishment, so somewhat site-specific) and local building law (less strict than the BEEM-UP targets in all three cases).

Besides these energy- and emission-centered targets, a more holistic evaluation based on the triple-bottom definition of sustainability is asked for in the project. The holistic assessment is to evaluate site-specific and culture-specific performance and later allow comparison of the three sites' relative performance and potential instead of applying fixed numbers. The methodology described and applied below was developed towards this goal. It is aimed to create a basis to identify the upscaling potential in the respective settings and is based heavily on the current state of life cycle assessment. The methodology therefore allows for a good picture of the current possibilities and existing barriers for life cycle assessment in the built environment, especially in the refurbishment sector.

Because of space limitations within this paper, only results from the Paris site are presented in this paper. The results for the other two sites are generally in line with the findings from the Paris site. Exceptions are specifically addressed within the text.

The results for the other sites as well as a number of additional results and figures for the Paris site can be found at the BEEM-UP homepage under www.beem-up.eu.

The Cotentin building is situated in Paris city center. It is in the 15th district, very close to Montparnasse train station and the peripheral motorway. The Cotentin building was built in the 1950s and has many technical flaws, especially in thermal and acoustic matters. It has eight floors and 87 apartments, ranging from a studio to three rooms. All apartments benefit of a double-exposition (north and south) but the typologies are very small. All flats have a small balcony, except for those on top floor that benefit from large terraces. A permanent caretaker lives and has an office in the building.

Common areas are quite limited: except for garbage and stroller rooms, there is only a room for the collective boiler and for attic storage.

The dwellings and common areas will be reorganized and embellished, including the refreshment of the flooring and wall covering in the dwellings and common areas, the creation of duplex apartments on the two top floors and the electric conformity of the whole building.

The typologies will be revised to fit today's living standards, and to take more benefits of the qualities of the building.

The facade from the 1950s is not marked as a cultural or historic heritage. It is therefore possible to install an outer insulation, and to search for an aesthetic finish.

\subsection{Insulation}

At the moment, there is no insulation on roof and front facade. A $6-\mathrm{cm}$ thick insulation was settled 15 years ago on the back facade. Double-glazed PVC windows were installed 15 years ago. The original ground-heating system with collective gas boilers is no longer efficient. There are leaks and it is not adjustable. The last few years, individual electric boilers were placed in the bathrooms. Mechanical ventilation is only available for the kitchens, but not the bathrooms.

\section{Methodology}

For all three sites within the BEEM-UP project, the application of active and passive technologies was assessed by internal experts from the building sector (mainly architects and engineers, but including site managers with economic background and experts for tenant involvement with a background in social science) in the beginning of the project, based on their experiences with various refurbishments. The technologies in question included housing services (heating, ventilation, domestic hot water generation and electrical equipment) and improvements of the envelope (insulation, improvements of air tightness, and exchange of windows and frames). Table 1 shows the measures identified as suitable and applicable for the site in Paris, France:

Great care was taken to identify sound measures that are feasible from a constructive point of view. As an example, insulation thicknesses were chosen that are available (e.g., $100 \mathrm{~mm}$ was chosen instead of $95 \mathrm{~mm}$ in the case of EPS insulation) and only options that are applicable were chosen (e.g., wall make-ups that are correct in terms of hygro- 
Table 1 Refurbishment measures for the Paris site

\section{Opaque areas}

\begin{tabular}{|c|c|c|c|c|}
\hline 1 Flat roof & Characteristics & Measure 1 & Measure 2 & Measure 3 \\
\hline \multirow[t]{7}{*}{ Area (Net) $575.40 \mathrm{~m}^{2}$} & Name of measure & Maintenance & $12 \mathrm{~cm}$ PUR (non-ventilated) & $20 \mathrm{~cm}$ EPS (non-ventilated) \\
\hline & Insulation type & No insulation & PUR & EPS \\
\hline & Lambda value insulation & - & $0.025 \mathrm{~W} /(\mathrm{mK})$ & $0.032 \mathrm{~W} /(\mathrm{mK})$ \\
\hline & Thickness insulation & $0 \mathrm{~mm}$ & $200 \mathrm{~mm}$ & $240 \mathrm{~mm}$ \\
\hline & Resulting $U$ value & $3.860 \mathrm{~W} /\left(\mathrm{m}^{2} \mathrm{~K}\right)$ & $0.121 \mathrm{~W} /\left(\mathrm{m}^{2} \mathrm{~K}\right)$ & $0.129 \mathrm{~W} /\left(\mathrm{m}^{2} \mathrm{~K}\right)$ \\
\hline & $€$ per unit & $92.00 €$ & $188.00 €$ & $200.00 €$ \\
\hline & Lifespan & $30.0 \mathrm{a}$ & $30.0 \mathrm{a}$ & $30.0 \mathrm{a}$ \\
\hline 2 Roof terrace & Characteristics & Measure 1 & Measure 2 & Measure 3 \\
\hline \multirow[t]{7}{*}{ Area (Net) $241.60 \mathrm{~m}^{2}$} & Name of measure & Maintenance & $\begin{array}{l}12 \mathrm{~cm} \text { PUR } 025 \\
\text { (non-ventilated) }\end{array}$ & $\begin{array}{l}16 \text { cm PUR } 025 \\
\text { (non-ventilated) }\end{array}$ \\
\hline & Insulation type & No insulation & PUR & PUR \\
\hline & Lambda value insulation & - & $0.025 \mathrm{~W} /(\mathrm{mK})$ & $0.025 \mathrm{~W} /(\mathrm{mK})$ \\
\hline & Thickness insulation & $0 \mathrm{~mm}$ & $120 \mathrm{~mm}$ & $160 \mathrm{~mm}$ \\
\hline & Resulting $U$ value & $3.860 \mathrm{~W} /\left(\mathrm{m}^{2} \mathrm{~K}\right)$ & $0.198 \mathrm{~W} /\left(\mathrm{m}^{2} \mathrm{~K}\right)$ & $0.150 \mathrm{~W} /\left(\mathrm{m}^{2} \mathrm{~K}\right)$ \\
\hline & $€$ per unit & $134.01 €$ & $194.60 €$ & $203.60 €$ \\
\hline & Lifespan & $30.0 \mathrm{a}$ & $30.0 \mathrm{a}$ & $30.0 \mathrm{a}$ \\
\hline 3 Ceiling cellar & Characteristics & Measure 1 & Measure 2 & Measure 3 \\
\hline \multirow[t]{7}{*}{ Area (Net) $738.71 \mathrm{~m}^{2}$} & Name of measure & Maintenance & $\begin{array}{l}\text { Ceiling insulation } \\
12 \mathrm{~cm} \text { EPS }\end{array}$ & $\begin{array}{l}\text { Ceiling insulation } \\
20 \mathrm{~cm} \text { EPS }\end{array}$ \\
\hline & Insulation type & No insulation & EPS & EPS \\
\hline & Lambda value insulation & - & $0.032 \mathrm{~W} /(\mathrm{mK})$ & $0.032 \mathrm{~W} /(\mathrm{mK})$ \\
\hline & Thickness insulation & $0 \mathrm{~mm}$ & $120 \mathrm{~mm}$ & $200 \mathrm{~mm}$ \\
\hline & Resulting $U$ value & $2.244 \mathrm{~W} /\left(\mathrm{m}^{2} \mathrm{~K}\right)$ & $0.238 \mathrm{~W} /\left(\mathrm{m}^{2} \mathrm{~K}\right)$ & $0.149 \mathrm{~W} /\left(\mathrm{m}^{2} \mathrm{~K}\right)$ \\
\hline & $€$ per unit & $0.00 €$ & $56.39 €$ & $67.44 €$ \\
\hline & Lifespan & $30.0 \mathrm{a}$ & $30.0 \mathrm{a}$ & $30.0 \mathrm{a}$ \\
\hline 4 External wall front & Characteristics & Measure 1 & Measure 2 & Measure 3 \\
\hline \multirow[t]{7}{*}{ Area (Net) $1176.43 \mathrm{~m}^{2}$} & Name of measure & Maintenance & Front EIFS EPS $10 \mathrm{~cm}$ & Front EIFS EPS $20 \mathrm{~cm}$ \\
\hline & Insulation type & No insulation & EPS & EPS \\
\hline & Lambda value insulation & - & $0.032 \mathrm{~W} /(\mathrm{mK})$ & $0.032 \mathrm{~W} /(\mathrm{mK})$ \\
\hline & Thickness insulation & $0 \mathrm{~mm}$ & $100 \mathrm{~mm}$ & $200 \mathrm{~mm}$ \\
\hline & Resulting $U$ value & $1.260 \mathrm{~W} /\left(\mathrm{m}^{2} \mathrm{~K}\right)$ & $0.255 \mathrm{~W} /\left(\mathrm{m}^{2} \mathrm{~K}\right)$ & $0.142 \mathrm{~W} /\left(\mathrm{m}^{2} \mathrm{~K}\right)$ \\
\hline & $€$ per unit & $32.00 €$ & $109.00 €$ & $138.00 €$ \\
\hline & Lifespan & $30.0 \mathrm{a}$ & $30.0 \mathrm{a}$ & $30.0 \mathrm{a}$ \\
\hline 5 External wall yard & Characteristics & Measure 1 & Measure 2 & Measure 3 \\
\hline \multirow[t]{7}{*}{ Area (Net) $1662.74 \mathrm{~m}^{2}$} & Name of measure & Maintenance & Yard EIFS EPS $10 \mathrm{~cm}$ & Yard EIFS EPS $20 \mathrm{~cm}$ \\
\hline & Insulation type & No insulation & EPS & EPS \\
\hline & Lambda value insulation & - & $0.032 \mathrm{~W} /(\mathrm{mK})$ & $0.032 \mathrm{~W} /(\mathrm{mK})$ \\
\hline & Thickness insulation & $0 \mathrm{~mm}$ & $100 \mathrm{~mm}$ & $200 \mathrm{~mm}$ \\
\hline & Resulting $U$ value & $1.332 \mathrm{~W} /\left(\mathrm{m}^{2} \mathrm{~K}\right)$ & $0.255 \mathrm{~W} /\left(\mathrm{m}^{2} \mathrm{~K}\right)$ & $0.142 \mathrm{~W} /\left(\mathrm{m}^{2} \mathrm{~K}\right)$ \\
\hline & $€$ per unit & $32.00 €$ & $109.00 €$ & $138.00 €$ \\
\hline & Lifespan & $30.0 \mathrm{a}$ & $30.0 \mathrm{a}$ & $30.0 \mathrm{a}$ \\
\hline $\begin{array}{l}6 \text { External wall } \\
\text { ground floor }\end{array}$ & Characteristics & Measure 1 & Measure 2 & Measure 3 \\
\hline \multirow[t]{5}{*}{ Area (Net) $277.40 \mathrm{~m}^{2}$} & Name of measure & Maintenance & $\begin{array}{l}\text { RDC curtain wall } \\
14 \mathrm{~cm} \text { EPS }\end{array}$ & $\begin{array}{l}\text { RDC curtain wall } \\
14 \mathrm{~cm} \text { PUR }\end{array}$ \\
\hline & Insulation type & No insulation & EPS & PUR \\
\hline & Lambda value insulation & - & $0.032 \mathrm{~W} /(\mathrm{mK})$ & $0.026 \mathrm{~W} /(\mathrm{mK})$ \\
\hline & Thickness insulation & $0 \mathrm{~mm}$ & $140 \mathrm{~mm}$ & $140 \mathrm{~mm}$ \\
\hline & Resulting $U$ value & $1.178 \mathrm{~W} /\left(\mathrm{m}^{2} \mathrm{~K}\right)$ & $0.191 \mathrm{~W} /\left(\mathrm{m}^{2} \mathrm{~K}\right)$ & $0.160 \mathrm{~W} /\left(\mathrm{m}^{2} \mathrm{~K}\right)$ \\
\hline
\end{tabular}


Table 1 (continued)

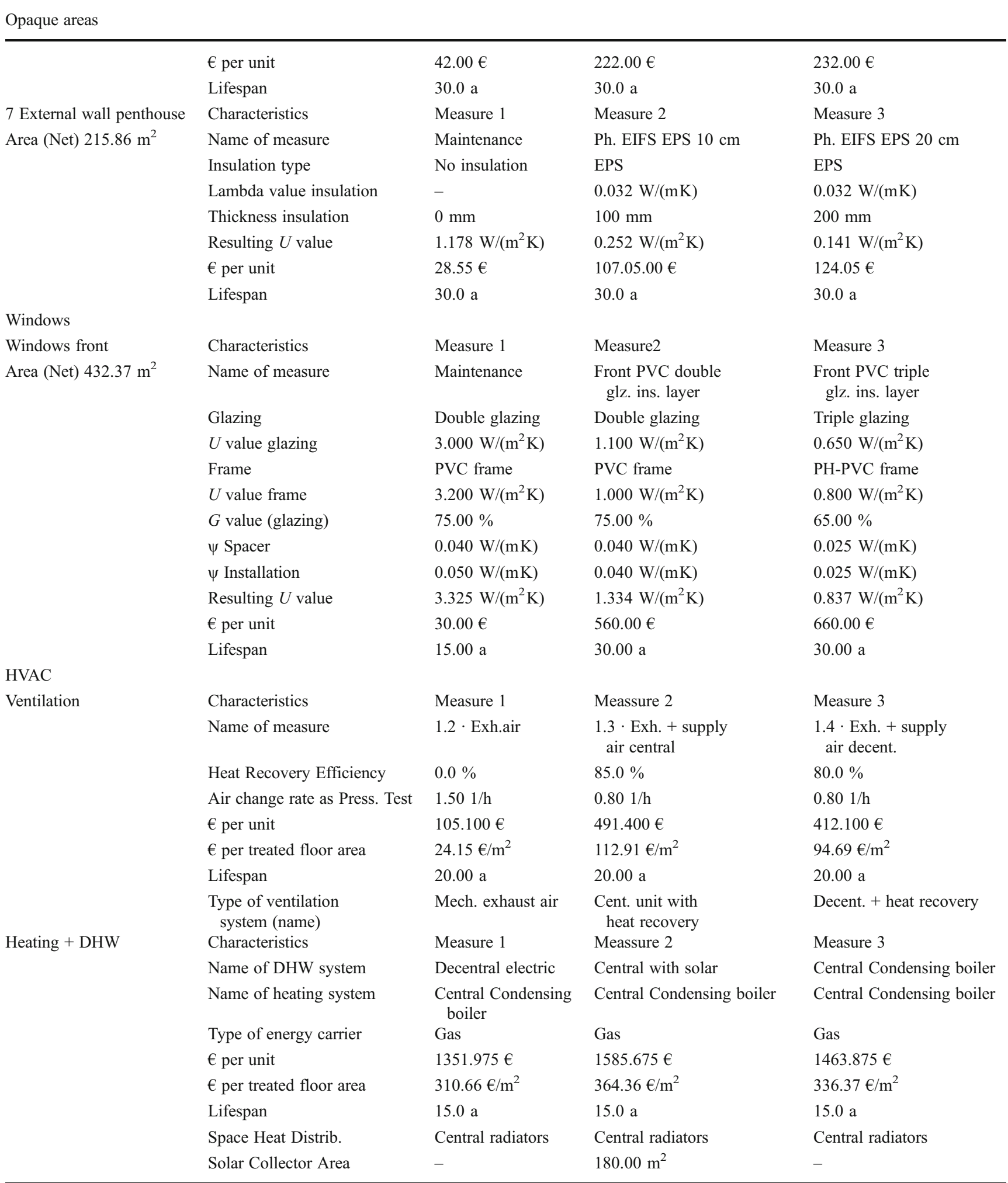

thermal behavior, insulation systems that can be applied to the existing walls, solutions that comply with local building law, etc.). In this way, each measure is already an optimized solution in its own field. One option for each measure covers work that would need to be done regardless of existing or threatening damage, as an "anyway solution". This 
option is always a minimal solution and marked as the base solution in the table above. The associated costs and material demands were assessed for all measures based on the recent experiences of the site managers. As a next step, the measures were combined with each other, resulting in a large number of refurbishment scenarios (a reduced number of 729 scenarios in the case of the site in Paris, France). The results were then analyzed and discussed with the decision makers.

The process can be taken from the flowchart below (Fig. 3).

\subsection{Calculation LCC}

For comparability of different results and useful benchmarking the $\mathrm{LCC}_{\mathrm{TFA}}$ are calculated according to the following formula:

$\mathrm{LCC}_{\mathrm{TFA}}=\frac{\mathrm{LCC}_{\mathrm{TOT}}}{\mathrm{TFA}}$

$\mathrm{LCC}_{\mathrm{TOT}}=I+\sum_{t=1}^{T}\left(\operatorname{LCf}_{t}\right) \cdot(1+i)^{-t}$

Calculation of periodic lifecycle cash flow

$\mathrm{LCf}_{t}=\mathrm{M}_{t}+\mathrm{A}_{t}+\mathrm{E}_{t}-\mathrm{R}_{t}$

1

Identification of possible technologie measures by experts (including site visit, analysis of construction plans and building law).

2

Assessment of costs and material demands for all identified technologies (based on recent project examples of the site managers.

3

Calculation of all combinations of the single technologie measures identified in step 1. Creation of the pareto optimal curve.

4

Analysis of the results and identification of promising overall concepts. Discussion with decision maker.

Fig. 3 Flowchart of information assessment and calculation process

$\begin{array}{ll}\text { TFA } & \text { Treated floor area } \\ \mathrm{LCC}_{\mathrm{TOT}} & \text { Total lifecycle costs } \\ \mathrm{I} & \text { Investment costs } \\ \mathrm{LCf}_{t} & \text { Life cycle cash flow in } t \\ i & \text { Discount rate (opportunity interest rate) } \\ T & \text { Periods under review } \\ A & \text { Annual operating cost (except energy costs) } \\ M & \text { Irregular maintenance and repair costs } \\ E & \text { Annual energy costs } \\ R & \text { Salvage/residual value }\end{array}$

Calculation Investment costs:

$I=I_{\mathrm{EV}}+I_{\mathrm{HVAC}}+I_{\mathrm{PL}}+I_{\mathrm{UF}}$

$I_{\mathrm{EV}} \quad$ Investment cost construction

$I_{\text {HVAC }}$ Investment cost for heating, ventilation, DHW, ICT

$I_{\mathrm{UF}} \quad$ Costs for unforeseen

$I_{\mathrm{PL}} \quad$ Planning costs

Table 2 shows the respective numbers used in the calculations. A timeframe of 30 a was chosen as this reflected the scope in which the partners were planning. As the methodology aimed to align with the existing internal planning routines, a respective timeframe was chosen even though other examples in this field calculate with longer timeframes (for example DGNB 50 a). A sensitivity study for 50 a can be viewed and downloaded on the BEEM-UP homepage (www.beem-up.eu).

Components with a lifetime shorter than $30 \mathrm{a} / 50$ a are exchanged after their lifetime expires.

\subsection{Calculation LCA}

The LCA is based on the masses of the building applied in the refurbishment measures. While the ecoinvent datasets include the material production as well as waste scenarios this system boundaries neglect transport of the material from factory to building site as well as the application process of the materials on the construction site.

Ecological indicators used within this paper (for more indicators see the BEEM-UP homepage)

- ReCiPe H/A (lifetime 30 years, static values for energy mix, source: ecoinvent database 2.2) (Ecoinvent 2.22010 )

Table 2 Reference case conditions for the LCC calculation

\begin{tabular}{ll}
\hline LCC & \\
\hline Periods under consideration & $30 \mathrm{a}$ \\
Energy price increase & $3.00 \% / \mathrm{a}$ \\
Inflation & $2.00 \% / \mathrm{a}$ \\
Total energy price increase & $5.00 \% / \mathrm{a}$ \\
Opportunity interest rate & $5.00 \% / \mathrm{a}$ \\
\hline
\end{tabular}


- IPCC 100 (lifetime 30 years, static values for energy mix, source: ecoinvent database 2.2) (Ecoinvent 2.2 2010)

- CED (Lifetime 30 years, static values for energy mix, source: ecoinvent database 2.2) (Ecoinvent 2.2 2010)

Table 3 lists the materials used in the LCA calculations for the refurbishment. The calculations were conducted with a wide selection of single and aggregated indicators. The selection of indicators for the project internal assessment was the result of the focus of the respective EU-framework asking for a focus on prime energy, $\mathrm{CO}_{2 \text { eq }}$ as well as for a "holistic" assessment.

The calculation for other indicators and several sensitivity studies can be studied and downloaded on the BEEM-UP homepage (www.beem-up.eu).

All calculations for the environmental LCA were conducted using static values, e.g., no change in energy mixes or changes in energy generation efficiency. The main reason for this is the fact that the heating systems assessed are gas or oil based condensing boiler technologies, and only a very limited improvement in this sector is likely in the foreseeable future. A dynamic calculation would therefore only differ minimally from a static one. The lifetime of all building materials exceeds 30 years in their specific application, so no renewal is taken into account.

For certain measures, a part of the cost could be the result of aspects that also contribute to other measures implemented. Such costs are allocated according to an economic allocation, based on the investment costs of the components affected.

The running consumption was calculated with the Passivehouse project tool (PHPP 2012). The life cycle inventory for the energy carriers in the usage phase again used static values.

The results of the calculation are visualized in a diagram (economic indicator on $Y$-axis, ecological indicator on $X$-axis) with the worst result being zero and the best result being the maximum value on the respective axes. All other results are weighted accordingly.

This normalization affects the shape of the data cloud and, assuming a Pareto curve, the shape of the Pareto curve. While this does not affect the ranking of overall concepts an approach with absolute numbers (e.g., without normalization) it takes away the possibility to assess the absolute tradeoff between the two assessed dimension (e.g., how much additional cost for how much emissions saved) instead

Table 3 Data sources for LCI and energy balances of the building in Paris, for all LCI Cutting losses $100 \%$ recycled into process. Post-consumer material considered $100 \%$ recycled into low grade applications [29]

\begin{tabular}{|c|c|c|}
\hline Process/Product & Remarks & Data source \\
\hline Natural gas & Natural gas, burned in boiler condensating, modulating $<100 \mathrm{~kW} / \mathrm{RER} \mathrm{S}$ & Ecoinvent $2.2(2010)$ \\
\hline electricity mix (Paris) & Electricity, low voltage, at grid/FR S & Ecoinvent $2.2(2010)$ \\
\hline EPS & Polystyrene foam slab, at plant/RER & Ecoinvent $2.2(2010)$ \\
\hline PVC & PVC B250/polyvinylchloride, bulk polymerised, at plant & Ecoinvent $2.2(2010)$ \\
\hline Cellulose & Cellulose Fiber, inclusive blowing, at plant/UCTE & Ecoinvent $2.2(2010)$ \\
\hline Wood fiber insulation & Fiber board, soft, at plant/UCTE & Ecoinvent $2.2(2010)$ \\
\hline XPS & Polystyrene, extruded (XPS), HFC-134a blown, at plant/RER & Ecoinvent $2.2(2010)$ \\
\hline Concrete & Concrete, normal, at plant/CH & Ecoinvent $2.2(2010)$ \\
\hline Plaster & Base plaster, at plant/CH & Ecoinvent $2.2(2010)$ \\
\hline Poor concrete & Poor concrete, at plant/CH & Ecoinvent $2.2(2010)$ \\
\hline Gypsum board & Gypsum plaster board, at plant/CH & Ecoinvent $2.2(2010)$ \\
\hline Construction wood & Sawn timber, hardwood, planed, kiln dried, $u=10 \%$, at plant/RER & Ecoinvent $2.2(2010)$ \\
\hline Plywood & Plywood, indoor use, at plant/RER & Ecoinvent $2.2(2010)$ \\
\hline Bitumen sealing for roof & Bitumen sealing V60, at plant/RER & Ecoinvent $2.2(2010)$ \\
\hline Steel & Steel, converter, unalloyed, at plant/RER & Ecoinvent $2.2(2010)$ \\
\hline Double glazing & Glazing, double (2-IV), $U<1.1 \mathrm{~W} / \mathrm{m}^{2} \mathrm{~K}$, at plant/RER $\mathrm{U}$ & Ecoinvent $2.2(2010)$ \\
\hline Triple Glazing & Glazing, triple (3-IV), $U<0.5 \mathrm{~W} / \mathrm{m}^{2} \mathrm{~K}$, at plant/RER $\mathrm{U}$ & Ecoinvent $2.2(2010)$ \\
\hline Window frame aluminum & Window frame, aluminum, $U=1.6 \mathrm{~W} / \mathrm{m}^{2} \mathrm{~K}$, at plant $/ \mathrm{RER} \mathrm{U}$ & Ecoinvent $2.2(2010)$ \\
\hline Window frame plastic & Window frame, plastic (PVC), $U=1.6 \mathrm{~W} / \mathrm{m}^{2} \mathrm{~K}$, at plant $/$ RER $\mathrm{U}$ & Ecoinvent $2.2(2010)$ \\
\hline Aluminum & Aluminum, production mix, wrought alloy, at plant/RER & Ecoinvent 2.2 (2010) \\
\hline $\begin{array}{l}\text { running energy demand during the } \\
\text { operation phase of the building }\end{array}$ & $\begin{array}{l}\text { Adapted version in order to deal with massive data. } \\
\text { No changes in formulas. }\end{array}$ & $\begin{array}{l}\text { Passive house calculation tool } \\
\text { (PHPP) (2012) }\end{array}$ \\
\hline climate data & Climate station Paris & METEONORM 6.1 (2012) \\
\hline
\end{tabular}


presenting a relative assessment (e.g., how much percent additional cost for how much percent of emissions saved).

The reason for the chosen approach was data security concern on part of the site managers in regard to the costs of the implemented measures. It was also found that the normalization actually is a benefit in the discussion with the planning team as discussion can focus on a general level and the advantages of certain overall concept instead of naming absolute costs first. It also allows for easier discussion between the different sites.

The chosen approach would become problematic if the absolute difference between the worst and the best concept would be too small. As the individual measures however range from simple maintenance (for example reparation of plaster) option to state-of-the art refurbishment (apply $20 \mathrm{~cm}$ of insulation) the absolute difference between best and worst in all cases actually surpasses the total costs of the worst measure.

\section{Results}

Figure 4 shows all 729 results, resulting from 6 measures, each with 3 possible options, for the indicators LCC and the LCA for ReCiPe for the site in Paris/France:

Each point in Fig. 4 represents an overall concept with either component $\mathrm{A}, \mathrm{B}$ or $\mathrm{C}$ for each of the six main measures taken into account. Each point and respective concepts has a certain performance in terms of LCC and environmental LCA that is resulting in its ranking on $Y$-axis or $X$-axis respectively and therefore its position in the cloud. A high ranking on one axis indicates a good performance for the respective indicator (e.g., low life cycle costs or a low environmental impact).

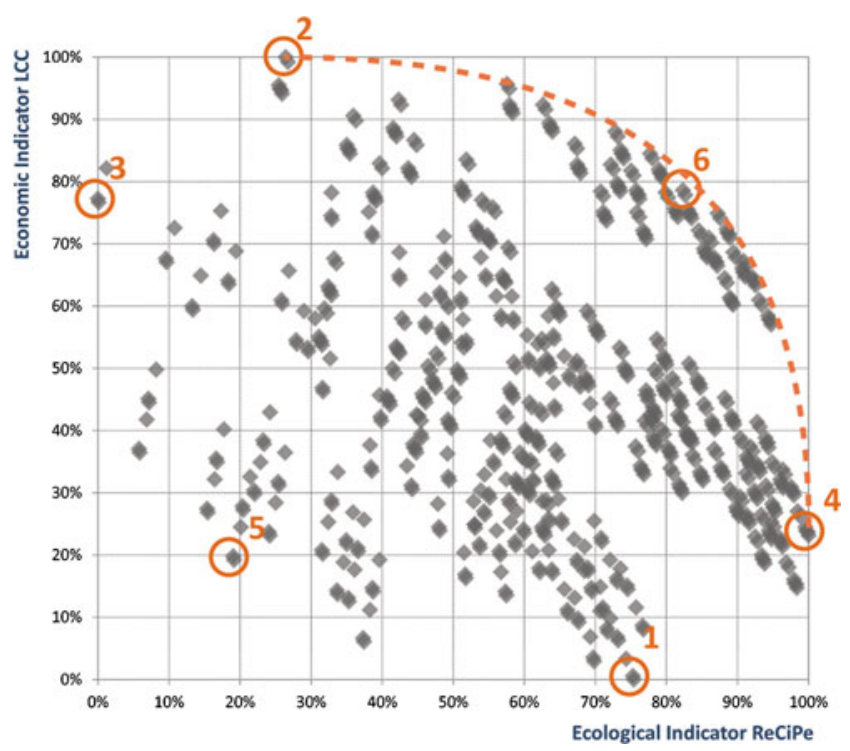

Fig. 4 Performance of all 729 concepts for the site in Paris/France according to LCC and ReCiPe including the assumed Pareto-optimal function for this setting
Points to the upper right therefore perform well in both dimensions while point to the lower left perform badly.

All results are normalized, with the worst result for both dimensions being 0 and the best being 100 accordingly.

The results of the assessment form a large cloud of points with generally environmentally promising results tending to be economically not well performing and vice versa. For many concepts, there are alternatives that are assessed as preferable in both dimensions. The most promising results form a curve that is marked with a dotted line. This line follows the original definition of Pareto-optimal data points for a data cloud in two-dimensional space.

Applied to the topic addressed within this paper it does not make sense to realize a concept that is surpassed in both the assessed indictors (e.g., environmentally less damaging and at the same time less costly).

There are several clusters of points within the cloud that are dominated by certain technologies (see below).

A number of concepts that mark special points in the data cloud (for example best economic performance, best environmental performance), are highlighted in Figs. 4 and 5a and b and discussed below. The technologies combinations that make-up the highlighted concepts can be taken from Table 4 .

Figure $5 \mathrm{a}$ and $\mathrm{b}$ show the same assessment for different environmental indicators (IPCC 2007100 a and CED, respectively) while applying the same frame conditions for the LCC as in Fig. 4.

The general impact of the chosen environmental indicator is medium to low. The difference between an assessment with CED and ReCiPe is especially minimal $(<5 \%)$. Some concepts with rather high running energy demand in the operation phase show a variation of up to $15 \%$ in relative performance when switching from ReCiPe to IPCC $2007100 \mathrm{a}$.

Figure 6a, b, c and d show the LCC/LCA ReCiPe assessment with certain technologies marked in color.

Some technology measures like window ventilation and insulation (6b) dominate entire clusters (6a). Most technologies, like the exchange of windows (6d), partial as opposed to full envelope insulation (6b) and ventilation (6a), are clearly favorable in one dimension while being less attractive in the other dimension (they perform environmentally well, while being expensive). Technology measures like solar hot water generation (6c) diffuse the entire cloud of concepts and do not create a huge impact on the overall performance.

\section{Discussion}

\subsection{Site-specific results}

The results are generally in line with the experience of the experts involved as far as the driving technologies are concerned 

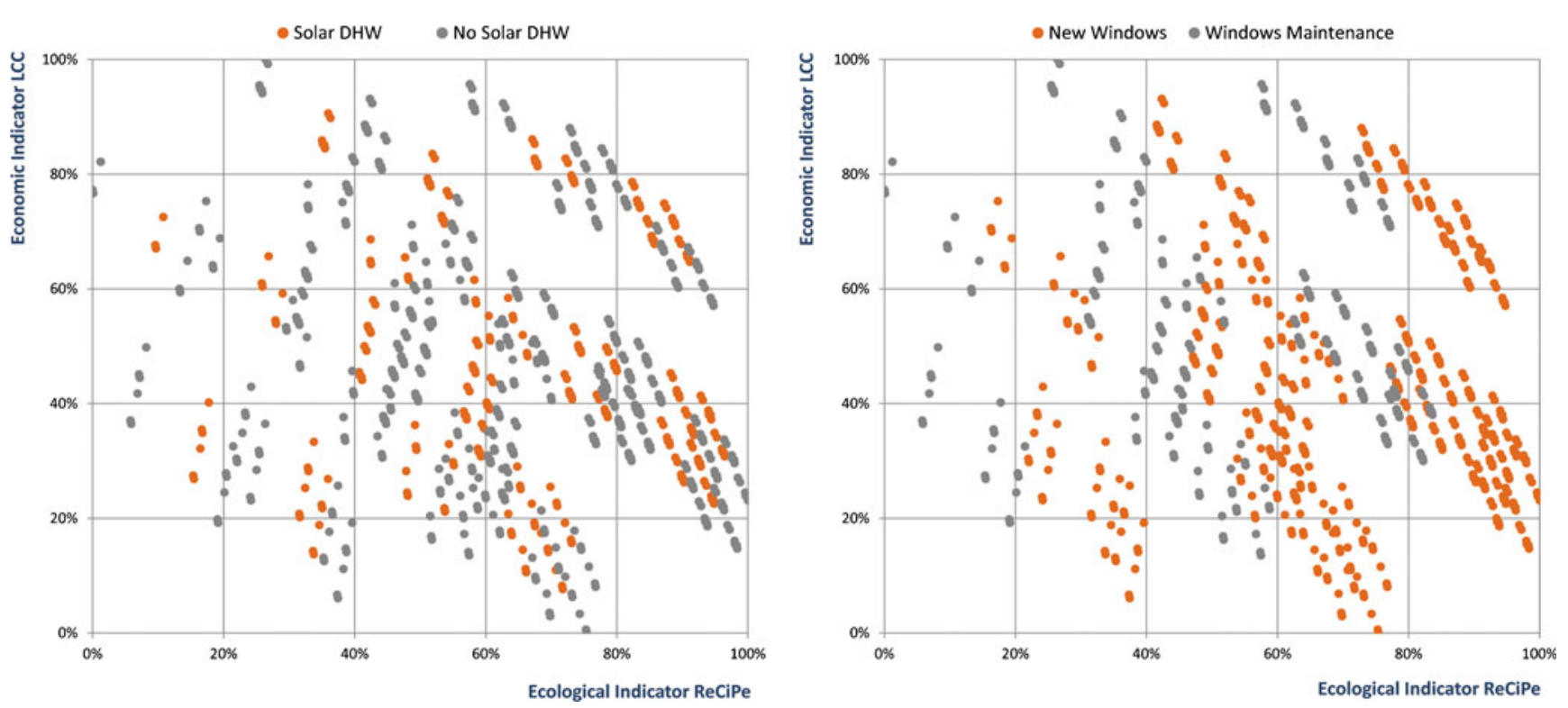

Fig. 5 Performance of all 729 concepts for the site in Paris/France according to LCC and CED (a) and LCC and IPCC 2007100 a (b) including the assumed Pareto-optimal function for this setting

Concerning the envelope and from an environmental viewpoint, the options that aim for a complete insulation of the building perform best. This way the material demand can be kept minimal with a maximum saving in the usage phase. However, in certain places, the allocation of insulation is much more expensive than in others. Economically, the best performing concepts are those that focus on applications that are cheap to apply, possibly with additional insulation in these places as a compensation for the parts that are not insulated. In this case, the compensation creates more material usage than in a complete insulation concept, lowering the overall environmental performance.

Sensitivity studies with changes in the life cycle from 30 to 50 a show the expected changes towards concepts with higher initial investment. None of the site managing companies worked with a strategic 50 a scope, the 30 a approach therefore matching much better with the company targets.

Sensitivity studies with investment costs, as opposed to LCC, clearly show that investment costs favor minimal measures that just cover the current problems while the lifetime view enabled by LCC is favors concepts that also show much better environmental performance. It can be concluded that an LCC method should be applied and an emphasis must be placed on the idea that investment models should be modified in order to allow investors to profit from savings in the usage phase as an incentive for them to apply LCC in their own models.

In the field of housing services, high-performing condensing systems are performing best regardless of their associated costs. The reason for this is the fact that it is extremely expensive to bring the envelope to a level that is comparable with the state of the art in new buildings.
Because of this and the large number of units attached to the heating system, an immense amount of running energy consumption remains, regardless of efforts in the envelope. This large amount of heat energy demand clearly favors the best possible systems available with which to cover this. Considering these results, it would have been worth investigating even more elaborate systems (PV-driven heat pumps with extensive underground collectors for example). These were however not found to be applicable in the first stage of the assessment by the experts because of the frame conditions (dense city, no possibility to conduct extensive ground works, legal frame conditions).

Ventilation plays a special part in these concepts, as controlled ventilation via a heat exchanger generally improves the environmental performance of buildings by saving heating energy but at a high economic cost, as many constructive measures must be applied in order to install the system, especially in the Paris site. A primary reason for implementing controlled ventilation in the building is actually the risk of mold as a result of the envelope being more airtight after the refurbishment - an aspect not within the scope of the applied indicators. This aspect was covered by the current social feasibility check (feedback and discussion with tenants and site manager) conducted in the methodology after the LCC/LCA calculation. The ventilation was in all three sites a major point of discussion in the meetings with the tenants. While the Swedish aim of achieving Passivehouse standard made ventilation mandatory the other two sites were intensively working with the tenants to discuss the tradeoff of between discomfort in the building phase and benefits in the usage phase afterwards. As largescale and therefore statistically solid data on the effect of 


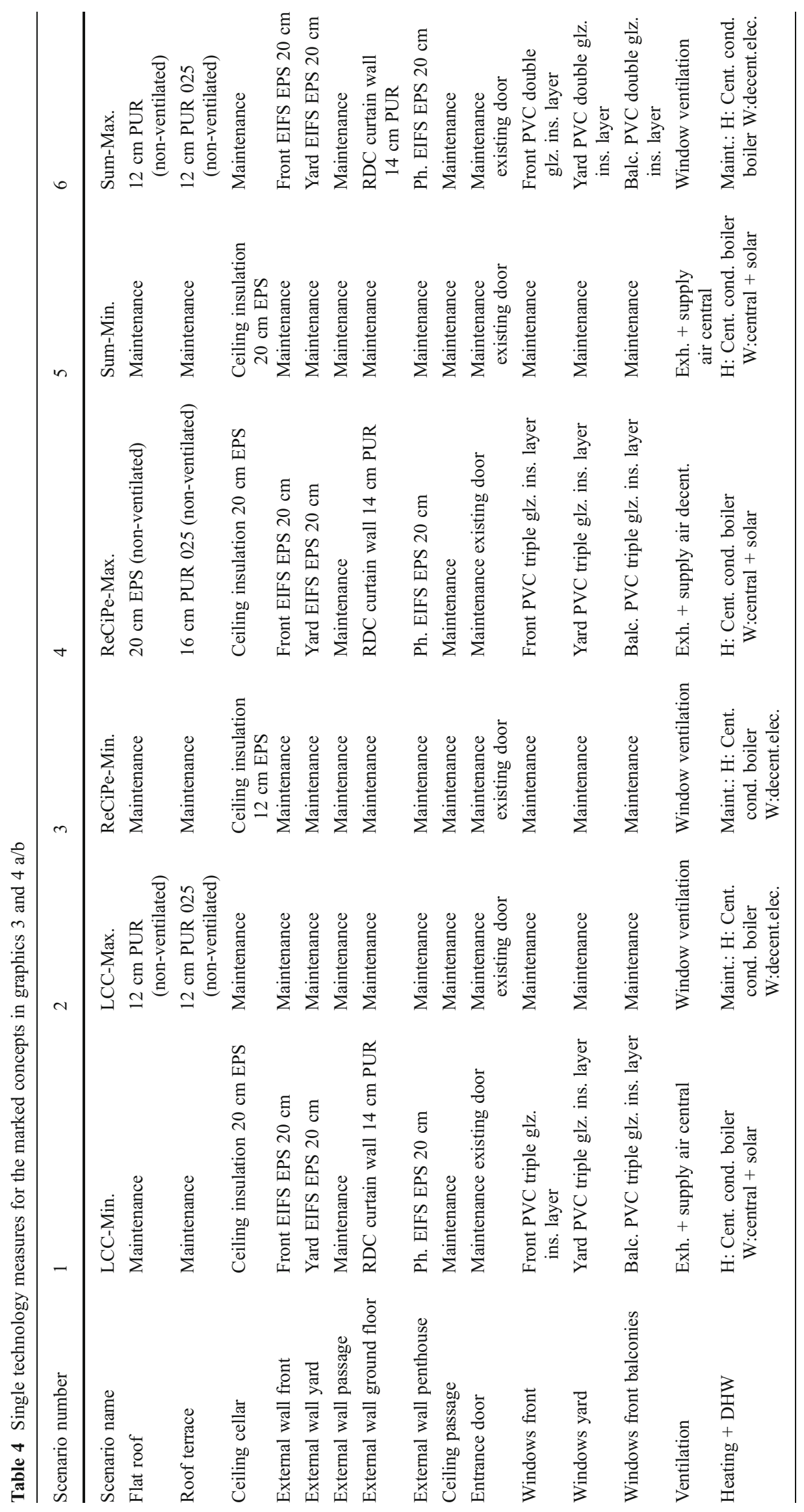



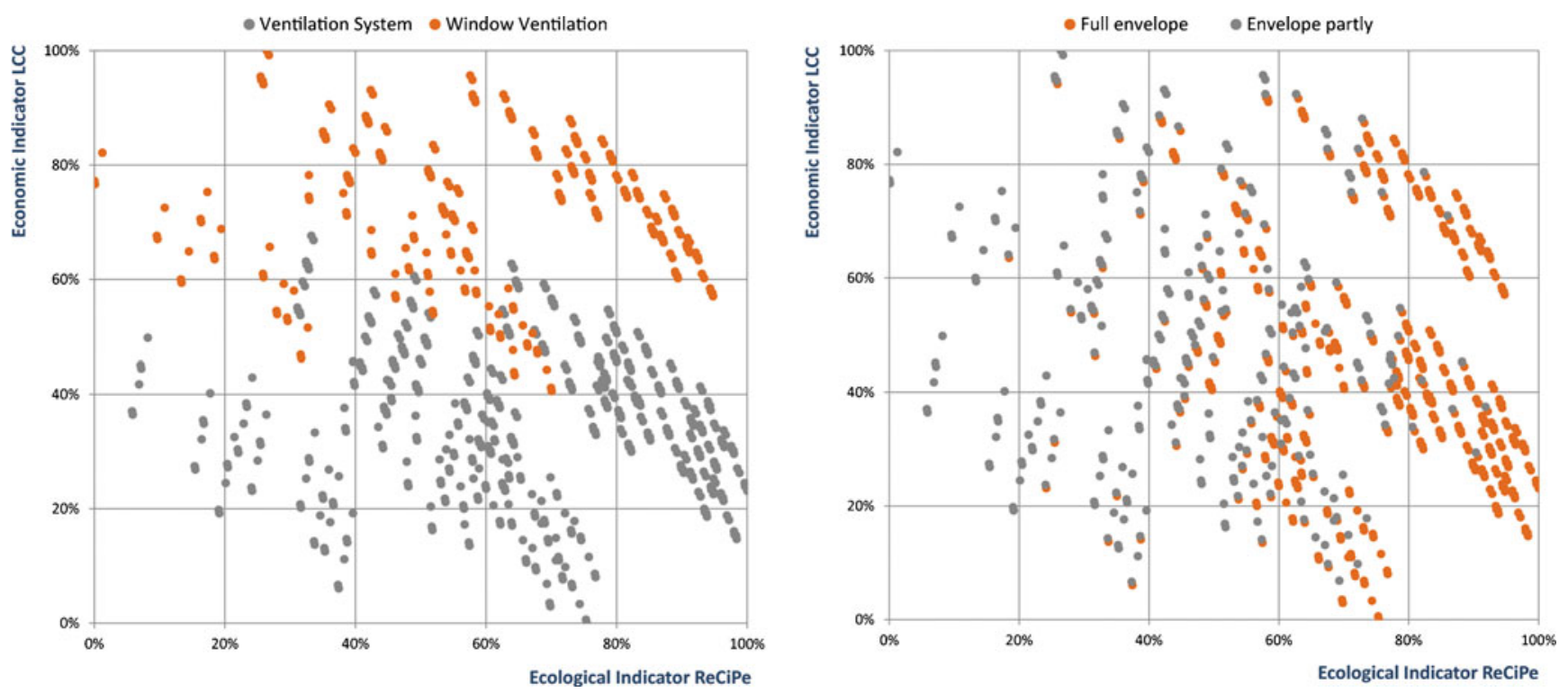

Fig. 6 Performance of all 729 concepts for the site in Paris/France according to LCC and IPCC with window insulation marked (a), full envelope insulation marked (b), solar domestic hot water generation marked (c) and exchange of windows marked (d)

regulated ventilation on comfort and health issues is not available the discussion remained on a qualitative level. The generation of such data has to be seen as important to better implement SLCA in building concepts.

6.2 Application potential of the methodology

and experience values within the project

In the case of the site in Paris, almost all concepts and scenarios would have met the hard targets set by the government for refurbishments. By applying a site-specific optimization approach and a life cycle based assessment, the final concept applied is performing substantially above the legislative targets. With a reduction of $78 \%$ in primary heat energy demand, compared to the original status, it also surpasses the target of the BEEM-UP project that is aiming to develop concepts in line with the 20-20-20 targets of the EU (2010).

Overall, the methodology was extremely helpful in identifying concepts that offer a sensible compromise, in terms of this paper an optimum. The experts involved were generally correct with their guesses of which combinations of technological measures would have the best performance, but their estimations of the exact ranking or the tradeoff between the two dimensions assessed were not very exact. Here, the methodology can provide valuable decision support and avoid wrong "educated guesses".

In general, the visualization of the tradeoff, made possible by the methodology, was very well received by the project partners and site managers. It was generally communicated that such a methodology could help bridge the factions of "energy efficiency just costs money" and "energy efficiency always pays off".

\subsection{Current weaknesses in the methodology}

There are several weaknesses in the current form of the methodology:

- Technologies and measures that are not taken into account in the initial assessment of potential options will of course not be assessed by the calculation routine. This might create gaps in the Pareto curve or even allow the assessment to miss promising options.

- The number of single technology measures that is initially named by the experts and therefore included in the calculation is currently rather small. The main reason for this is limited processing power. This weakness is one of the easiest to compensate for in the future by increases in performance of available hardware.

- The results are currently visualized with relative values as percentages. In order for this to make any sense, the difference between the lowest and highest performance should be meaningful. This must be ensured by the experts.

- The calculation uses static values for the energy mix and respective LCI data. Changes in the energy mixes can make a big difference in the results and are very likely to occur in the lifetime of a building

- So far, the tool includes no dynamic implementation of different future energy price scenarios. These of course are very relevant for the LCC.

- Most importantly, the social dimension is left out of the calculation so far. This is especially critical as some of the concepts that are performing badly do in fact have some very relevant advantages in terms of user friendliness and resilience to user behavior. 


\section{Conclusion and outlook}

\subsection{Conclusions}

The form of the tradeoff curve is promising. The very nature of the tradeoff is beneficial in a way that much can be gained in the other dimension, with the first steps away from the economic and environmental maximum towards an overall optimum. This is a strong argument for both sides not to stick to extreme scenarios.

Derivations from the ideal curve can also describe areas of exceptionally great potential (highs) or low potential (valleys) accordingly. Areas of such potential can be defined as ones with the highest values for $\sqrt{\mathrm{LCA}^{2}+\mathrm{LCC}^{2}}$ and are very likely the ones that the discussion with decision makers will focus on while avoiding areas of low potential (low values for $\sqrt{\mathrm{LCA}^{2}+\mathrm{LCC}^{2}}$.

The following visualization, Fig. 7, shows the basic concept and also introduces terms for the transfer of the methodology to three dimensions in the outlook:

Clearly, there is an area of concepts that are out of question. This would include all concepts for which there are better performing alternatives in both dimensions, and which offer no additional benefits.

As opposed to the concepts aiming for a maximal performance, in graphic six defined as a performance of $>95 \%$ in one or both dimensions, the optimal concepts perform better from an overall viewpoint. There are no concepts in the area of strong sustainability (both dimensions $>95 \%$ ). The exact extent of the improvement can be assessed either by comparing the delta for the economic dimension and the delta for the environmental dimension or the delta of the vector described by $\sqrt{\mathrm{LCA}^{2}+\mathrm{LCC}^{2}}$.

Regardless of the concept chosen, a certain minimal improvement will be achieved even when going for maximum concepts. The approach of an optimum however aims far beyond the minimal improvement.

\subsection{Outlook}

There are several improvements of the methodology to aim for in the future. As discount rates and energy price scenarios drive the economic calculations based on LCC, there is an aim to implement these in a more dynamic way, allowing a change of factors and immediately visualizing the effect this change has on the curve.

The same is true for the future development of the energy mixes and the related LCI data.

Based on this, a kind of uncertainty or error ratio is to be implemented at least on the Pareto-optimal level or for especially promising concepts (highs on the Pareto-optimal curve).

Furthermore, the future concepts should be assessed based on all three pillars of sustainability by including
Fig. 7 Principal graphic of the findings

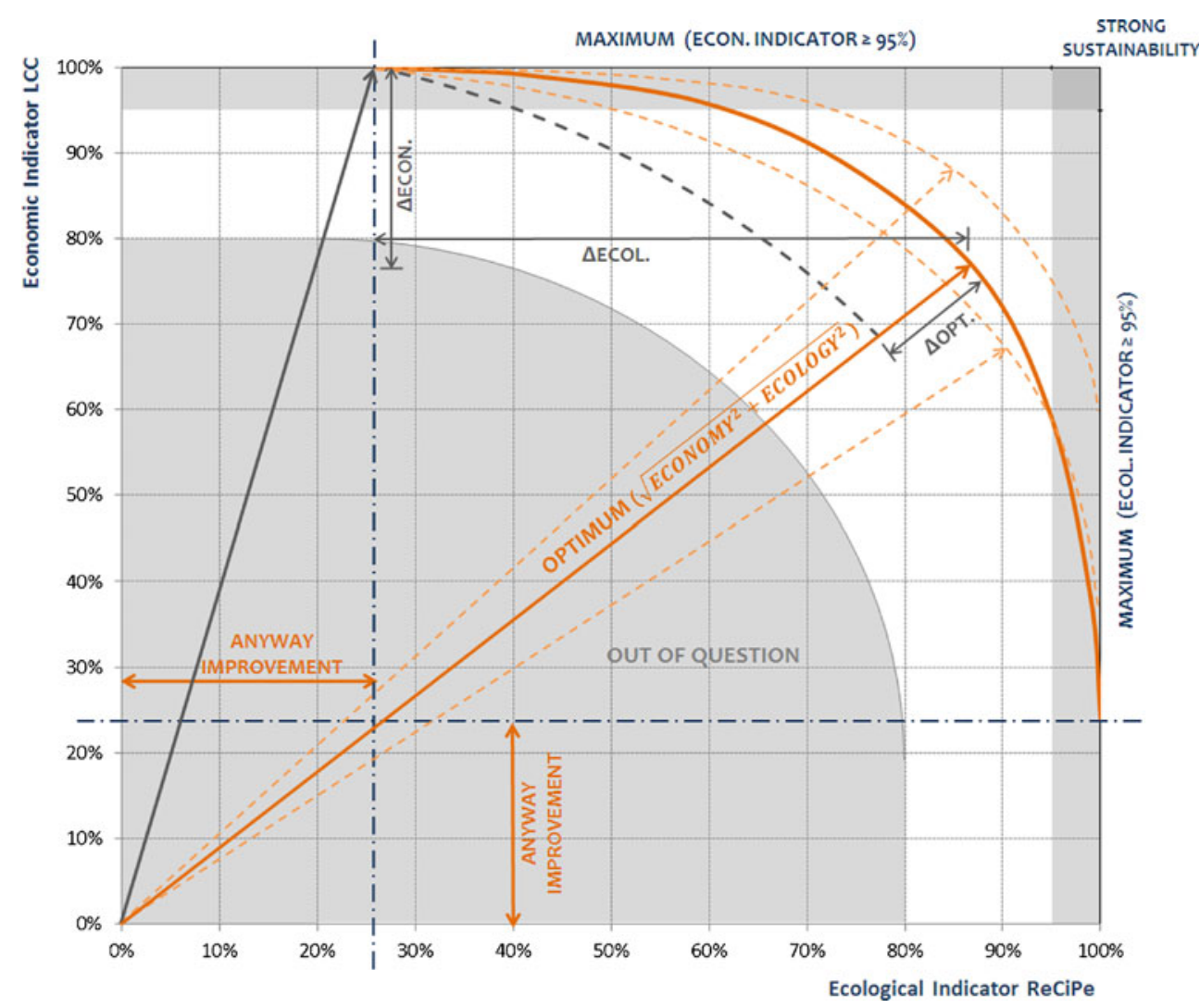


SLCA. This would vastly improve the impact of the tool and bring it in line with the holistic concept of sustainability.

In order to visualize the results, a 3D model can be proposed with one dimension of sustainability assigned to each axis. A possible visualization could look like Fig. 8 .

The first stage of calculation will, as in the twodimensional example, result in a large cloud of points in a now three-dimensional space. However, when taking away all points for which alternatives exist and which perform

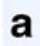

a

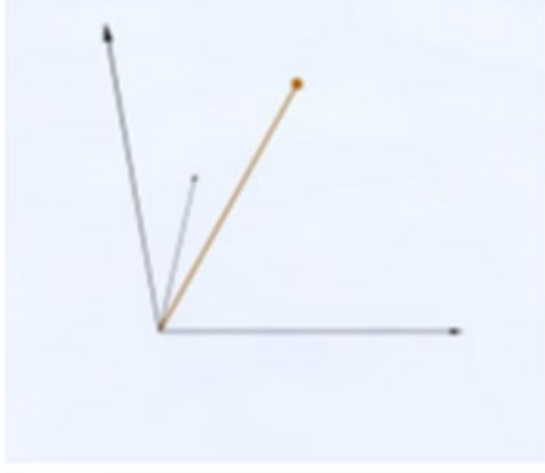

b

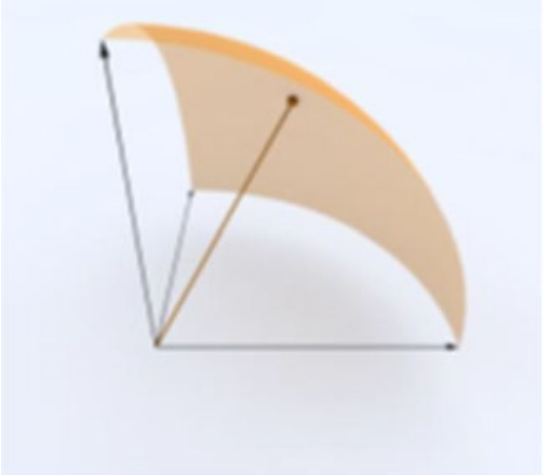

c

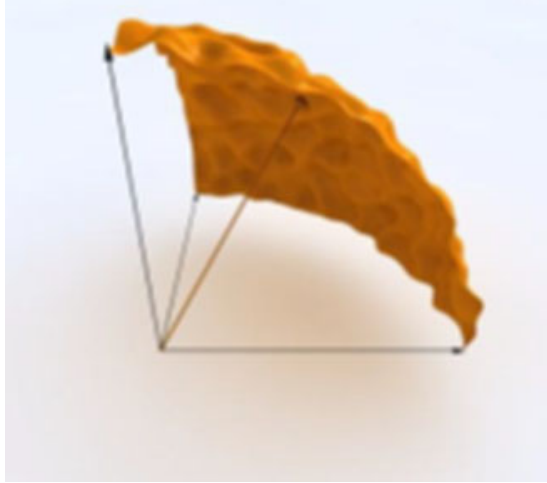

Fig. 8 The general principle of multidimensional Pareto optimization a single result (point), b ideal visualization of Pareto-optimal results, $\mathbf{c}$ realistic shape of Pareto-optimal results better in all three dimensions (the Pareto-optimal ones) a form would surface, which resembles a section of a globe. The exact shape of the surface would be heavily dependent on the options assessed and the tradeoffs between them. It is very likely that the surface would be rough, having high and low sections, marking areas of high potential and areas that, even while being Pareto-optimal, should be avoided.

To create such a visualization, life cycle assessments for all three dimensions should be applied in order to come up with feasible results.

In order to come up with a visualization of the results, two options exist. The first one would follow a rating according to the formula $\mathrm{LCSA}_{\text {target }}=$ $\sqrt{\mathrm{LCA}^{2}+\mathrm{LCC}^{2}+\mathrm{S}-\mathrm{LCA}^{2}}$, (basically calculating the length of the vector in three-dimensional space), giving each Pareto-optimal option a rating by assigning a number.

The other option would be a visual one, taking the Pareto-optimal surface and applying it to two-dimensional space as a kind of map with contour lines.

Both solutions would have their advantages, with the number rating showing the typical characteristic of an end point assessment, while the graphic solution would allow the decision maker deciding in favor of a concept biased towards a certain pillar instead of only an overall rating.

\subsection{Social indicators in the building sector}

In order to solidly implement SLCA in the building sector, the development of suitable indicators should be promoted (Kloepffer 2008). Currently, social issues in the building sector are taken into account mainly qualitatively and not quantitatively. In the first building labels, like DGNB, a certain number of points can be achieved by implementing measures that in the widest sense benefit the residents, the local community or the society as a whole. Again, this follows an idea of maximization and hard targets.

In order to successfully implement a thinking of site tailored optimization, qualitative approaches need to be established for the application of SLCA in the building sector.

A big problem in this regard will be the extreme dependence and differentiation of regional and cultural conditions (Zamagni et al. 2011). This is seen as a primary reason why such a methodology or, especially, a set of suitable criteria has not been established in the building sector so far

Fundamentally, the following ethical objectives should be considered:

- Precautionary principle

- Reversibility principle

- Polluter pays principle and producer responsibility

- Protecting the vulnerable

- Protecting the rights of the nonhuman world 
Social criteria, in the context of buildings or building materials, can then be related to the production of the material or its usage phase, and the operation phase of the result (the building). In both systems direct and indirect impacts should be differentiated. In regard to the production phase, workers are directly affected, for example by work conditions, harmful substances and emissions, etc. In the operation phase, the user will be affected accordingly (comfort, health, etc.).

For both fields, solid data is currently missing and needs to be generated by further research.

It must be admitted that, while it can be generally assumed that certain measures are beneficial or at least not harmful, the exact effect is not known or at least not measurable within current indicators. Examples for such measures are half-private meeting zones or similar measures intend to create a good atmosphere and exchange between residents or employees.

There needs to be a discussion about which aspects ought to somehow be implemented into SLCA for the building sector and which aspects are better left entirely to architects and planners, whose job it would then be to assure social acceptance for sustainable buildings by including them in their work and in competitions.

Acknowledgments The authors express their gratitude for the fruitful discussion and support within the BEEM-UP project team. The site managers of all three sites are acknowledged for their invaluable support in the development of the methodology and the creation of this paper.

Open Access This article is distributed under the terms of the Creative Commons Attribution License which permits any use, distribution, and reproduction in any medium, provided the original author(s) and the source are credited.

\section{References}

Aktas C, Bilec M (2012) Service life prediction of residential interior finishes for life cycle assessment. Int $\mathrm{J}$ Life Cycle Assess 17(3):362-371

Allacker K (2012) Environmental and economic optimisation of the floor on grade in residential buildings. Int J Life Cycle Assess $17: 813-827$

BEEM-UP (2012) www.beem-up.eu (accessed on 20.04.2012)

Blengini G, Di Carlo T (2010) Energy-saving policies and low-energy residential buildings: an LCA case study to support decision makers in Piedmont (Italy). Int J Life Cycle Assess 15(7):652-665

BREEAM (2012) http://www.breeam.org (accessed 20.04.2012)

COE (2012) Council of Europe Framework Convention on the Value of Cultural Heritage for Society CETS No.: 199.http://conventions. coe.int/Treaty/Commun/QueVoulezVous.asp?NT=199\&CM= $8 \& \mathrm{DF}=04 / 01 / 2012 \& \mathrm{CL}=\mathrm{ENG}$ (accessed on 9 January 2012)

DGNB (2012) Deutsche Gesellschaft für Nachhaltiges Bauen; online under: http://www.dgnb.de/_en/certification-system/Criterias Overview/Criterias_Overview.php (accessed 20.04.2012)

DIN EN 18599 (2007) DIN EN 18 599-Energetic Evaluation of Buildings
Dreyer L, Hauschild M, Schierbeck J (2006) A framework for social life cycle impact assessment. Int J Life Cycle Assess 11(2):88-97

Dumreicher H, Kolb B (2008) Place as a social space: fields of encounter relating to the local sustainability process. J Environ Manag 87(2):317-328

Ecoinvent 2.2 (2010) Ecoinvent data version 2.2. website: www.ecoinvent.ch

EU (2010) 20/20/20 Strategypaper of the EU, online under: http:// ec.europa.eu/clima/policies/brief/eu/package_en.htm $>$ (accessed 17.11.2010)

European Commission (2010) Energy-efficient buildings PPP, multiannual roadmap and longer term strategy

Feige A, Wallbaum H, Krank S (2011) Harnessing stakeholder motivation: towards a Swiss sustainable building sector. Build Res Inf 39(5):504-517

Femenías P, Lindén A-L (2011) Energy efficiency in public housing in sweden: integrated strategies to overcome market barriers. In: Niebor N, Tsenkova S, Gruis V, van Hal A (eds) Energy efficiency in housing management. Earthscan

Frontczak M, Andersen RV, Wargocki P (2012) Questionnaire survey on factors influencing comfort with indoor environmental quality in Danish housing. Build Environ 50:56-64

Güttinger H, Kasser U (2009) Forum Chriesbach: Graue Energie und Stromverbrauch gleichbedeutend. Bau- \& Energie-markt, pp 174 179 (in German)

UN Habitat (2008) UN Habitat UE. Housing the poor in Asian Cities Nairobi, Bangkok: UN Habitat, UN ESCAP

Jörgensen E (2009) Att värma bostäder. Påverkansfaktorer och beslut [Heating Homes: Influencing 792 Factors and Decisions]. Elforsk: Stockholm

Kaatz E, Root DS, Bowen PA, Hill RC (2006) Advancing key outcomes of sustainability building assessment. Build Res Inf 34(4):308-320

Kloepffer W (2008) Life cycle sustainability assessment of products. Int J Life Cycle Assess 13(2):89-95

Kreditanstalt für Wiederaufbau (2012) Credit conditions from the KfW (Kreditanstalt für Wiederaufbau, Germany) in 2012. Online under http://www.kfw.de/kfw/de/Inlandsfoerderung/Programmueber sicht/Energieeffizient Bauen/index.jsp (accessed 04/2012)

LEED (2012) Leadership in Energy and Environmental Design; online under: http://www.usgbc.org/DisplayPage.aspx?CMSPageID= 1989 (accessed 20.04.2012)

Maite Cabeza G (1996) The concept of weak sustainability. Ecol Econ 17(3):147-156

Maliene V, Malys N (2009) High-quality housing - a key issue in delivering sustainable communities. Build Environ 44(2):426-430

Marceau M, VanGeem M (2006) Comparison of the life cycle assessments of an insulating concrete form house and a wood frame house. J ASTM Int 3(9):1-11

Meijer F, Itard L, Sunikka-Blank M (2009) Comparing European residential building stocks: performance, renovation and policy opportunities. Build Res Inf 37(5-6):533-551

METEONORM 6.1 (2012) online under: www.meteonorm.ch (accessed 20.04.2012)

MINERGIE (2012) Standards in Switzerland, online under: http:// www.minergie.ch/standard_minergie.html (accessed 04/2012)

Optis M, Wild P (2010) Inadequate documentation in published life cycle energy reports on buildings. Int J Life Cycle Assess 15(7):644-651

Ostermeyer Y, Schryver AD, Wallbaum H (2011) Optimal insulation thicknesses for the 25 European countries based on environmental indicators; peer reviewed conference paper and oral presentation, ISIE 2011, accepted for oral presentation, University of California, Berkeley, 06/2011

Passivhaus Institut (2012) www.passiv.de (accessed on 18.11.2012)

PHPP (2012) Passivehaus Projektierungspaket; online available under: www.passiv.de (accessed on 20.04.2012) 
Reitinger C, Dumke M, Barosevcic M, Hillerbrand R (2011) A conceptual framework for impact assessment within SLCA. Int J Life Cycle Assess 16(4):380-388

Saling P, Kicherer A, Dittrich-Krämer B, Wittlinger R, Zombik W, Schmidt I, Schrott W, Schmidt S (2002) Eco-efficiency analysis by BASF: the method. Int J Life Cycle Assess 7(4):203218
UNEP (2003) Sustainable building and construction. UNEP Ind Env 26:2-3

Wu H, Yuan Z, Zhang L, Bi J (2012) Life cycle energy consumption and $\mathrm{CO} 2$-eq emission of an office building in China. Int $\mathrm{J}$ Life Cycle Assess 17(2):105-118

Zamagni A, Amerighi O, Buttol P (2011) Strengths or bias in social LCA? Int J Life Cycle Assess 16(7):596-598 